\title{
The Exploration of the Organizational Justice Level and Its Relation with Cyberloafing with a Study in the Healthcare and Treatment Network
}

\author{
Hossein Samadi-Miarkolaei *1(D), Hamzeh Samadi-Miarkolaei ${ }^{2}$ \\ 1. MA, Young Researchers and Elite Club, Qaemshahr Branch, Islamic Azad University, Qaemshahr, Iran \\ 2. PhD, Department of Public Administration, Science and Research Branch, Islamic Azad University, Tehran, Iran
}

\begin{tabular}{|c|}
\hline Article Info \\
\hline $\begin{array}{l}\text { Received: 2020/06/14; } \\
\text { Accepted: 2020/09/02; } \\
\text { ePublished: 2020/09/22 }\end{array}$ \\
\hline doil 10.30699/jergon.8.3.13 \\
\hline $\begin{array}{l}\text { Use your device to scan } \\
\text { and read the article online }\end{array}$ \\
\hline 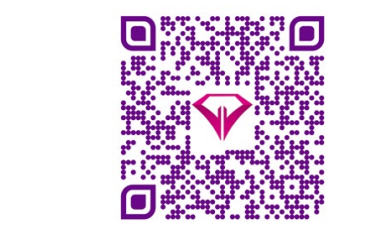 \\
\hline
\end{tabular}

Corresponding Author Hossein Samadi-Miarkolaei MA, Young Researchers and Elite Club, Qaemshahr Branch, Islamic Azad University, Qaemshahr, Iran

Email:

hossein_samadi22@yahoo.com

\begin{abstract}
Background and Objectives: Nowadays, the healthcare and treatment sector's organizations are known as one of the most important pillars in the debate of public health. The psychological development of the experienced, knowledge-driven, competent, proactive and motivated, and empowered human resource is the most important competitive advantage of these organizations. Taking this matter into account as the importance of human resources, the present research tried to explore the employees' psychological perception of organizational justice and its impacts on the cyber loafing in Babolsar healthcare and treatment network.
\end{abstract}

Methods: In terms of purpose, the present research is an applied study, and in terms of method, an analytical-correlational study. Considering the simple random sampling method and on the basis of Cochran's Formula, 165 employees of Babolsar healthcare and treatment network were studied in 2018. To collect the data, two standard scales for cyber loafing and organizational justice were used. Data analysis was done using Pearson's correlation and Structural Equation Modeling by SPSS and LISREL.

Results: Research results showed that there is a negative and significant relation between organizational justice and cyber loafing $(P<0 / 001, \mathrm{r}=-0 / 299)$. The results of structural equation modeling also showed that organizational justice variable explains the $47 \%$ of variance for cyber loafing variable. The values of goodness of fit indices for research model are $\left(\chi^{2} / \mathrm{df}=1.44 ; \mathrm{GFI}=0.98 ; \mathrm{NFI}=0.98 ; \mathrm{RMSEA}=0.054\right)$ that showed desirable fitness of model.

Conclusion: The cyber loafing is increasingly impressed by organizational justice and its components, and in this regard, the employees are more vulnerable. Therefore, it is suggested that the managers develop the organizational procedures and the methods of justice establishment in organization, and eventually, apply the capacities of their human resource in the best way possible.

Keywords: Organizational justice, Cyberloafing, Human resources, Healthcare and treatment network

Copyright $(C) 2020$, This is an original open-access article distributed under the terms of the Creative Commons Attribution-noncommercial 4.0 International License which permits copy and redistribute of the material just in noncommercial usages with proper citation.

\section{How to Cite This Article:}

Samadi-Miarkolaei H, Samadi-Miarkolaei H. The Exploration of the Organizational Justice Level and Its Relation with Cyberloafing with a Study in the Healthcare and Treatment Network. Iran J Ergon. 2020; 8 (3): 13-21 
بررسى سطح عدالت سازمانى و ارتباط آن با كَتزنى اينترنتى با مطالعهاى در شبكةُ بهداشت و درمان

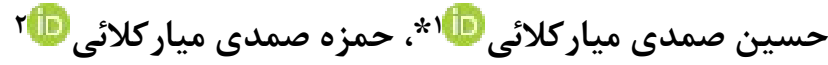

' . . كارشناسى ارشد، باشگاه يزوهشكران جوان و نخبكان، واحد قائمشهر، دانشگاه آزاد اسلامى، قائمشهر، ايران

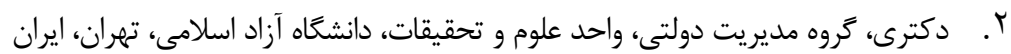

\begin{tabular}{|c|c|}
\hline خلاصه & 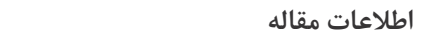 \\
\hline 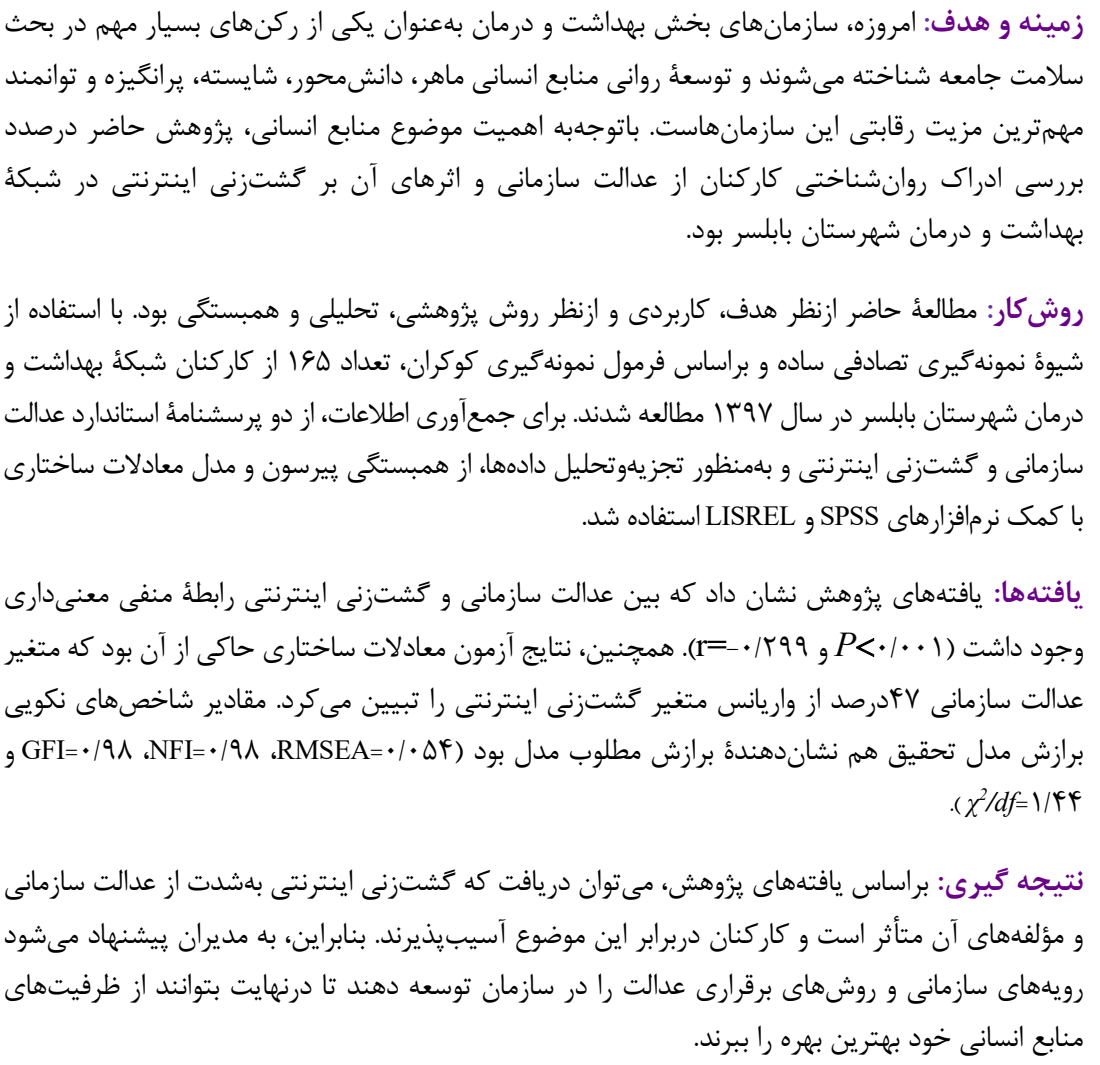 & 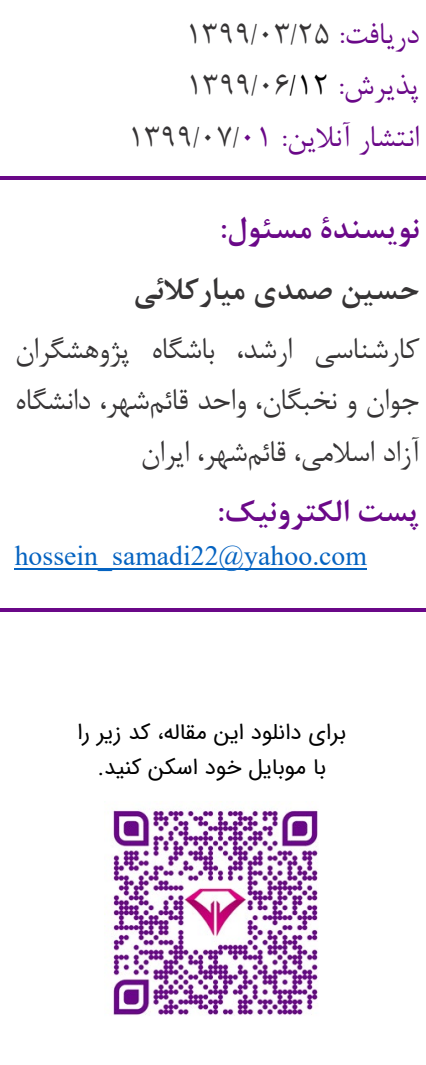 \\
\hline كليدوازهها: عدالت سازمانى، گشتزنى اينترنتى، منابع انسانى، شبكهُ بهداشت و درمان & \\
\hline
\end{tabular}

مقدمه

نظريه احساس افراد را درباره منصفانهبودن نحوه رفتار با خودشان و عان ديخران طبقهبندى و تشريح مى كند؛ احساسى كه براى بهبود

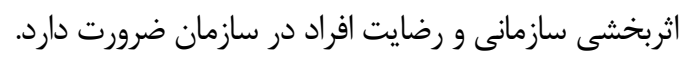


نظر مى

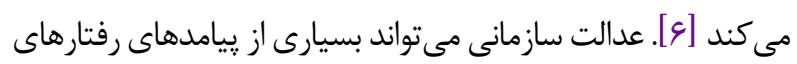
سازمانى و عملكردهاى شغلى را تشريح كند. به موازات كسترش و و ييشرفت جامعهُ بشرى، ديدگاههاى مربوط به عدالت تكامل يافته و دامنأ آن از ديدكاههاى اديان و فلاسفه به تحقيقات تجربى دئ كشيده
امروزه، نيروى انسانى متعهد و وفادار زمينهها را براى رشد و توسعُ سازمانى فراهم مى كند و حتى وجهئ سازمان را در جامعه بهبود مىبخشد و درنهايت، به اثربخشى بيشتر و بهرهورى سازمان

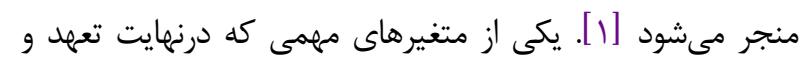
وفادارى و بهرهورى منابع انسانى را براى سازمان ها بهارمغان مى آرود،

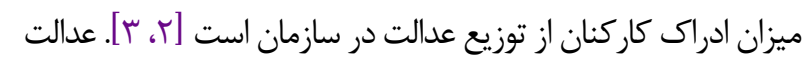

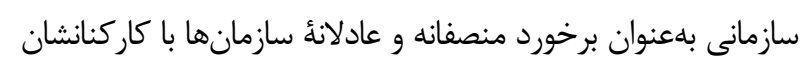

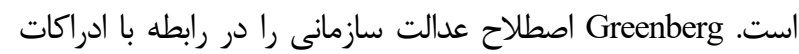




اثرهاى مخربى بر زمان، كار ايیى، تعهد سازمانى كار كنان و عملكرد

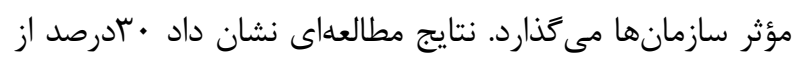

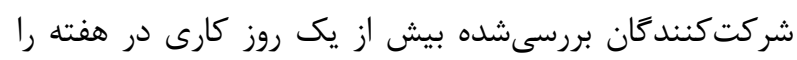

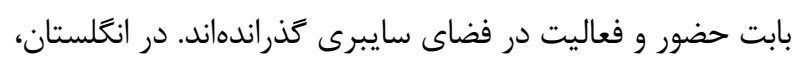

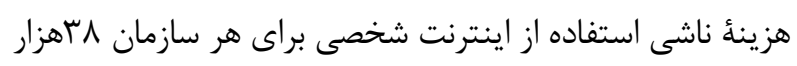


زده مىشود [بر إ].

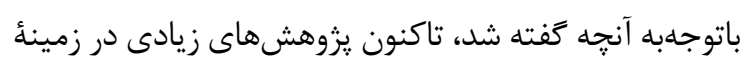

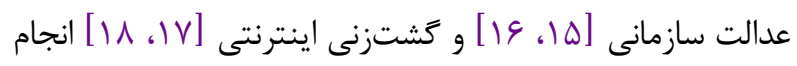

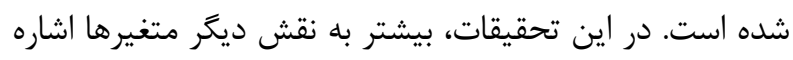

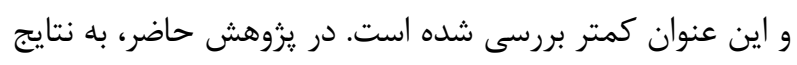

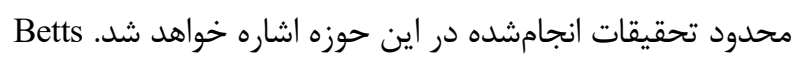

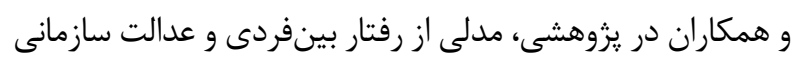

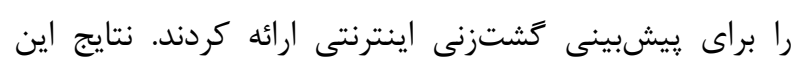

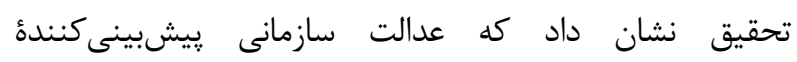
درخورتوجهى براى قصد كشتزنى اينترنتى بود؛ درحالى كه ابعاد

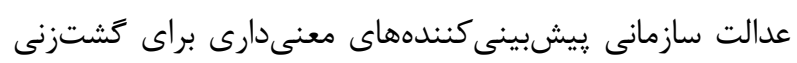

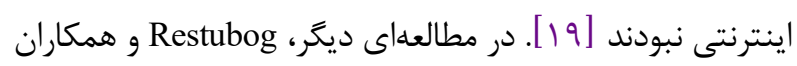

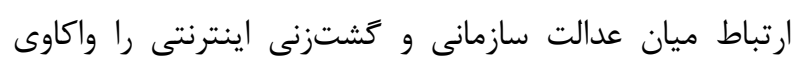



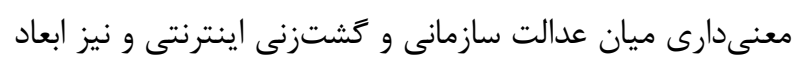

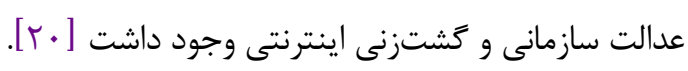
De Lara

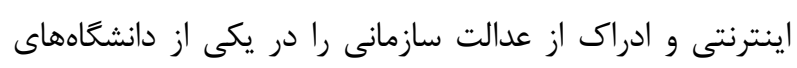



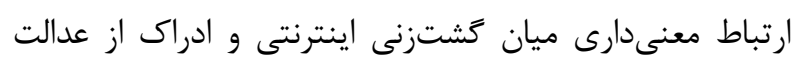

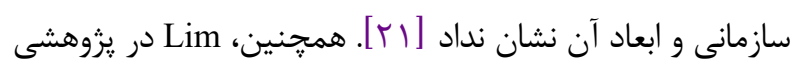
با موضوع "افناورى اطلاعات راهى براى طفرهرفتن در انجام كاربه،

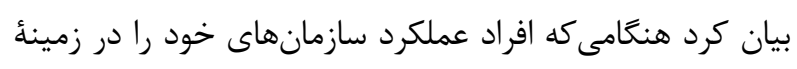

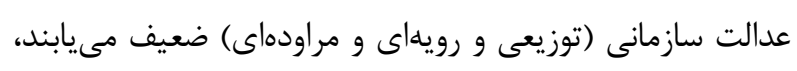

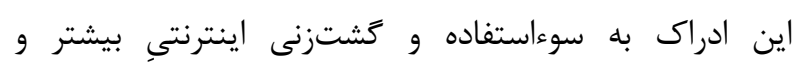

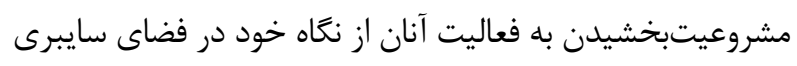
منجر مىشود [1 [1]. براساس نتايج متفاوت و متضاد بيانشده، اين يرسش مطرح

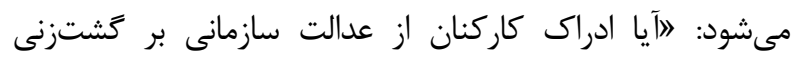

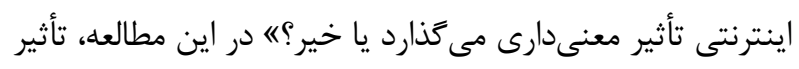

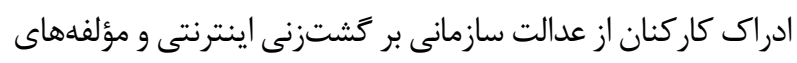
آن در شبكهُ بهداشت و درمان شهرستان بابلسر بررسى شانى شد.
شده است. ناگفته نماند اجراى عدالت در جامعه منوط به وجود

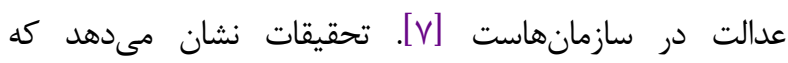

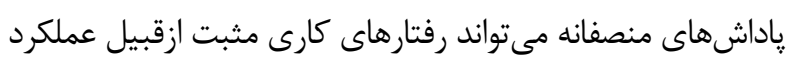

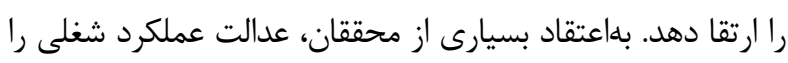

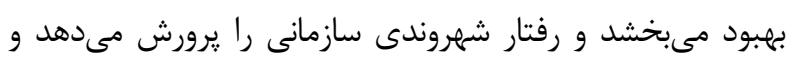

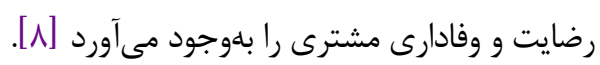
تاكنون، محققان ابعاد متفاوتى براى تبيين عدالت در سازيت مازدان

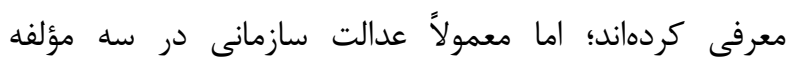

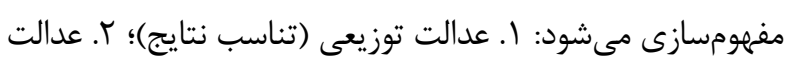

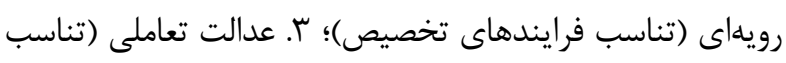

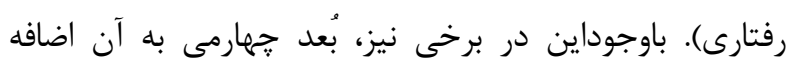

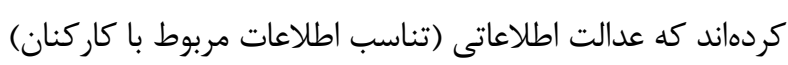

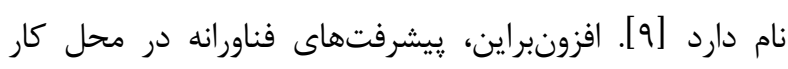

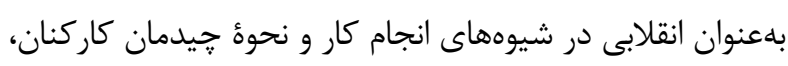

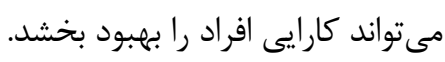



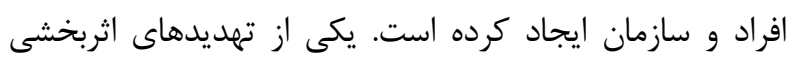

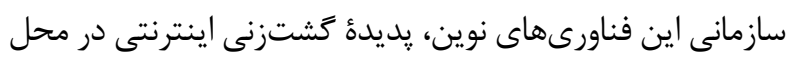

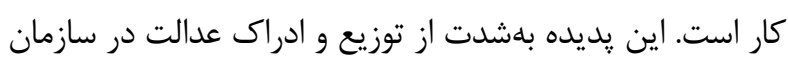

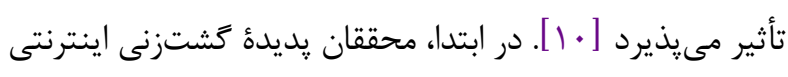

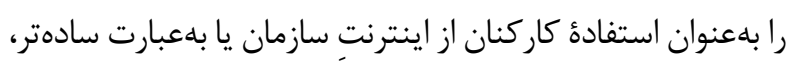

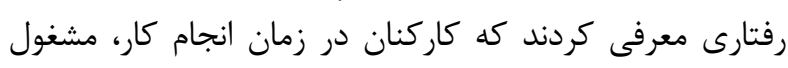

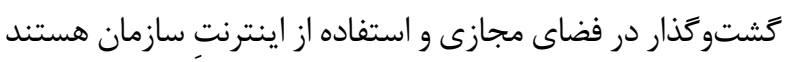

$\left[\begin{array}{lll}11 & 0\end{array}\right]$

از زمان انتشار يديدة كشتزني اينترنتى در ادبيات دانشخاهى،

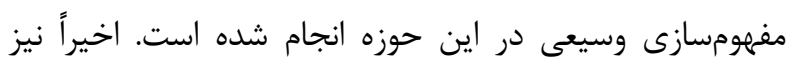

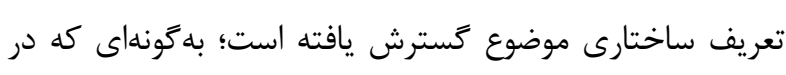

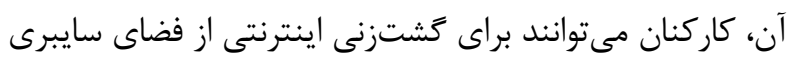

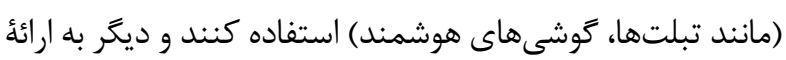

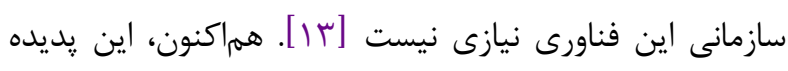

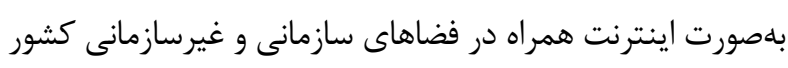

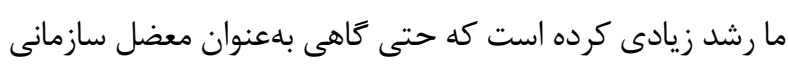

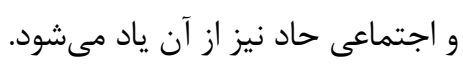

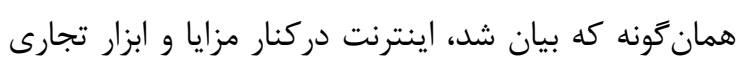

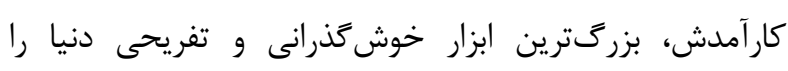



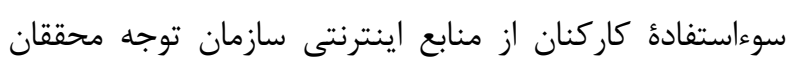

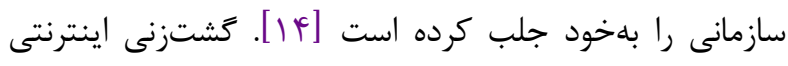


اينترنتى روزانه شما در ساعات كارى به ارسال ايميلهاى نامرتبط با كار تعلق دارد؟

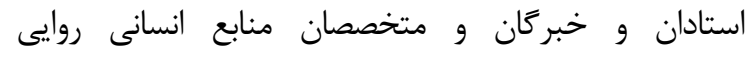

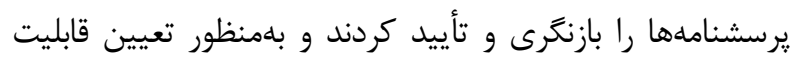

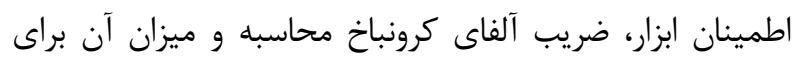

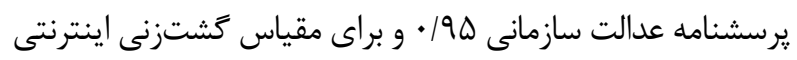

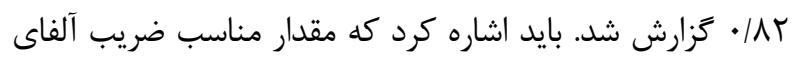

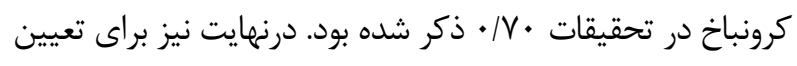

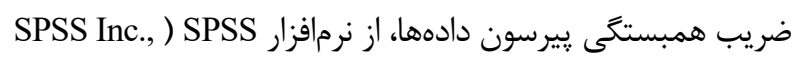
(Chicago, IL., USA

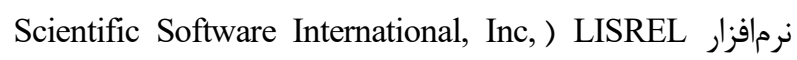
(Chicago, IL.,

\section{يافته ها}

باتوجهبه اينكه ب أ1 نفر از كاركنان شبكأ بهداشت و درمان

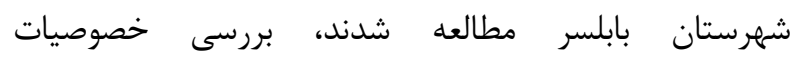

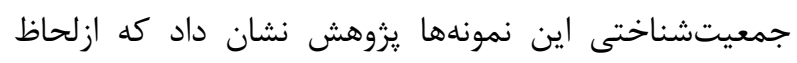

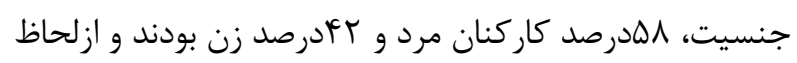

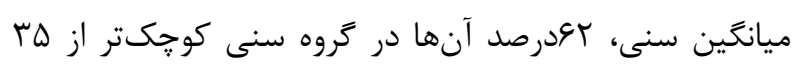

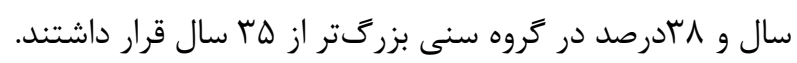
همجنين، مدرى تحصيلى الددرصد كاركنان كارشناسى و و

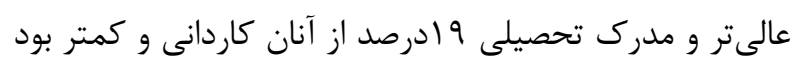



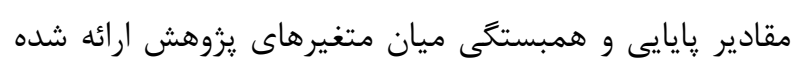

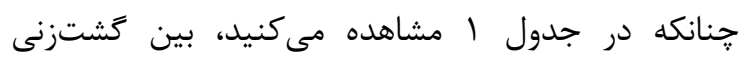

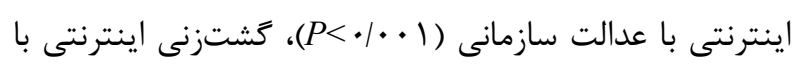



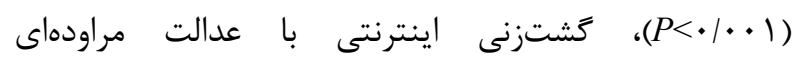

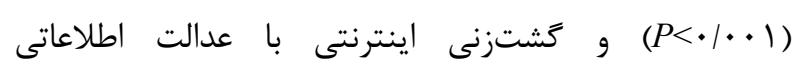

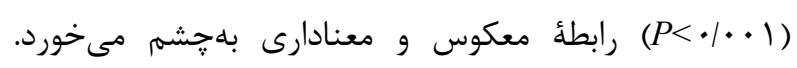

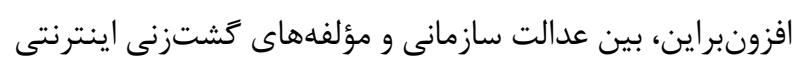

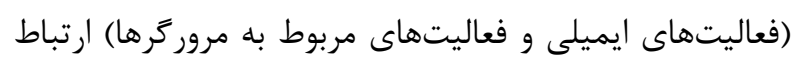

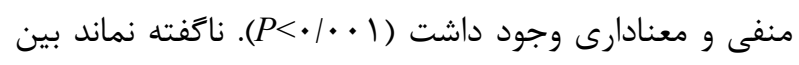

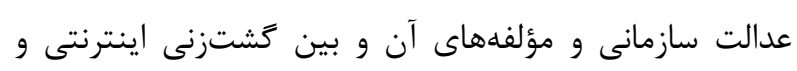

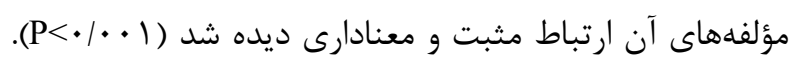

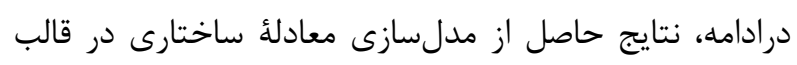
جداول و تصوير ارائه مىشود.
روش كار

تحقيق حاضر ازنظر هدف، كاربردى و ازنظر روش يزوهشى،

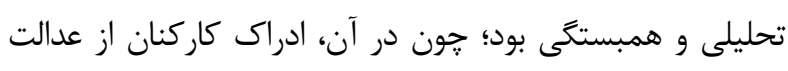

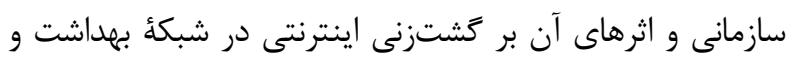

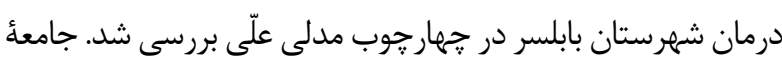

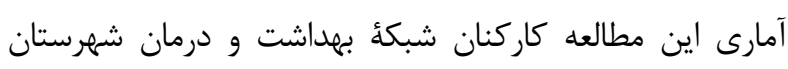

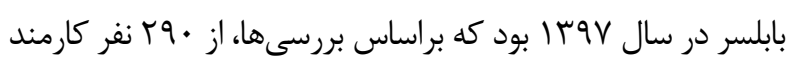

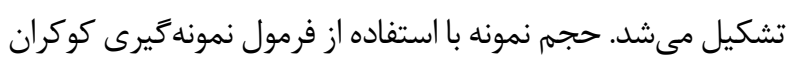

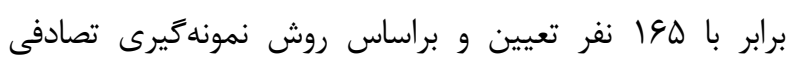

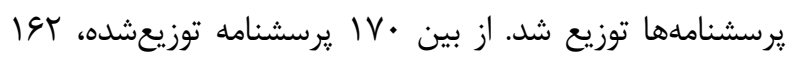



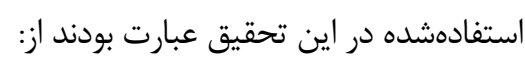

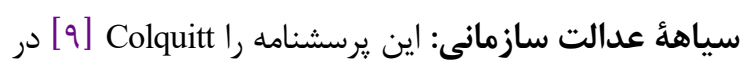

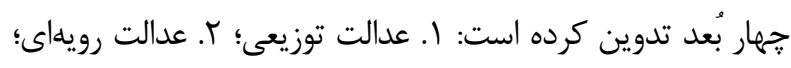

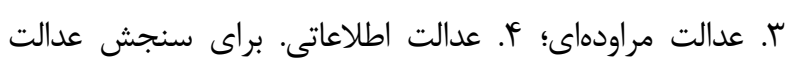

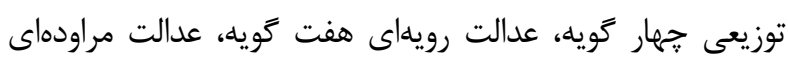

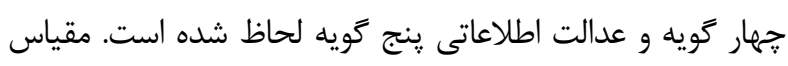

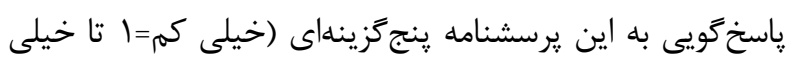

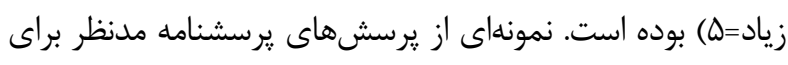
هر مؤلفه بلهترتيب زير است:

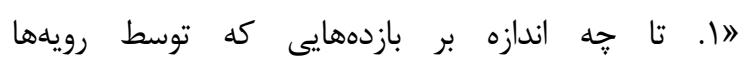

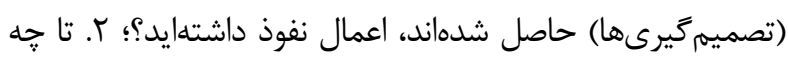

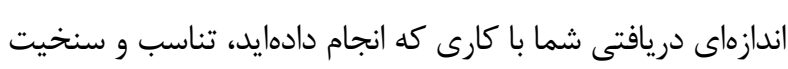

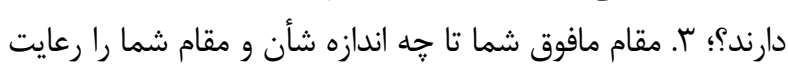

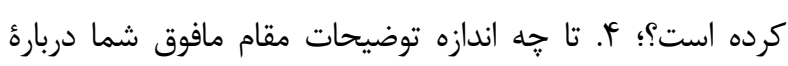
رويهها مستدل بودهاند؟



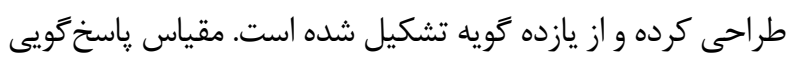

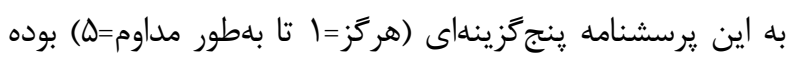

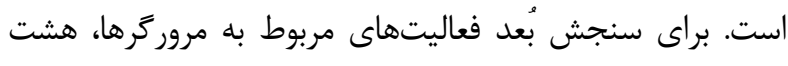

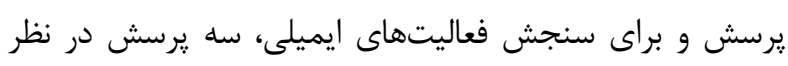

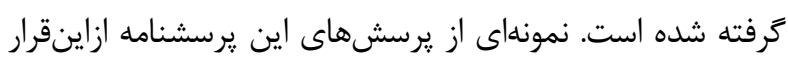
است:

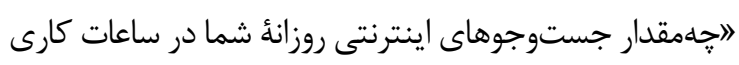

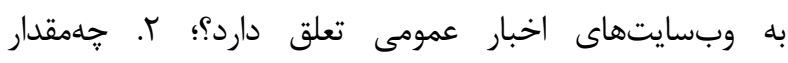

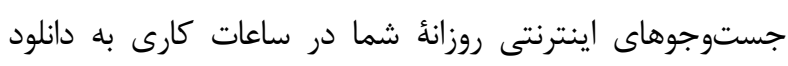

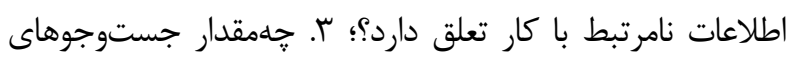




\begin{tabular}{|c|c|c|c|c|c|c|c|c|c|}
\hline$\Lambda$ & $\checkmark$ & 9 & $\Delta$ & p & $r$ & $r$ & 1 & متغير هاى بزوهش & رديف \\
\hline & & & & & & & $(\cdot \mid \Lambda T)$ & كشتزنى اينترنتى & 1 \\
\hline & & & & & & $(\cdot \mid \wedge \Gamma)$ & $\cdot \mid \Lambda F V^{* *}$ & فعاليتهاى مرورگرها & r \\
\hline & & & & & $(\cdot \mid \wedge \cdot)$ & $\cdot|4 \wedge|^{* * *}$ & $\cdot / V \Gamma \Lambda^{* * *}$ & فعاليتهاى ايميلى & $r$ \\
\hline & & & & $(\cdot / 9 T)$ & $-\bullet /$ MTY**: & $-\cdot 1 \cdot 09$ & $-\cdot 1194^{*}$ & عدالت رويهاى & f \\
\hline & & & $(\cdot / 91)$ & $\cdot / \mathcal{F} \wedge \uparrow^{q * * *}$ & $-\cdot / r \Delta \Delta^{* * *}$ &.$- / 191 *$ & $-\cdot|Y F|^{\text {䋨 }}$ & عدالت توزيعى & $\Delta$ \\
\hline & & $(\cdot / 9 \cdot)$ & $\cdot|r T|^{* \frac{* 0}{*}}$ & 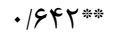 & $-\bullet / r \vee q^{*}$ &.$- / 1 \mathrm{fr}$ & 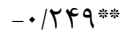 & عدالت مراودهاى & 9 \\
\hline & $(\cdot / 94)$ &  & $\cdot / 1 \vee \varphi^{*}$ & $\cdot 109 \cdot$ & $-\cdot / \& F D^{* * * *}$ & $-\cdot / Y V 9^{* *}$ & $-\cdot / \Gamma \vee 9^{* * *}$ & عدالت اطلاعاتى & $\checkmark$ \\
\hline$(\cdot / 90)$ & $\cdot \mid \Lambda \mu \cdot * *$ & $\cdot|\wedge \Delta|^{* * * *}$ & $\cdot|09|^{* * * *}$ & $\cdot / 9 \wedge 9 * *$ & $-\cdot$ AYY & $-\cdot / \Lambda \wedge V^{*}$ & $-\cdot / \Upsilon 99 \%$ & عدالت سازمانى & $\wedge$ \\
\hline
\end{tabular}

در آزمون مدلسازى معادلات ساختارى، بلمنظور بررسى مدارى برازندگى مدل يزوهش شاخصهاى برازندگى مختلفى وجود دارد.

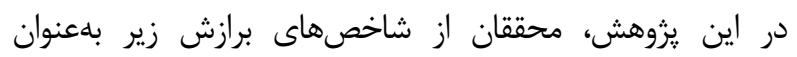

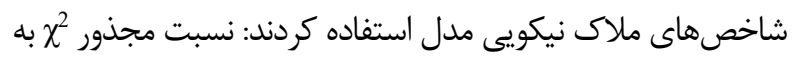

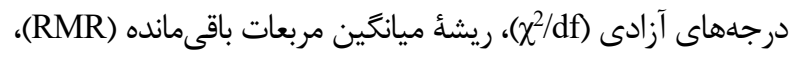

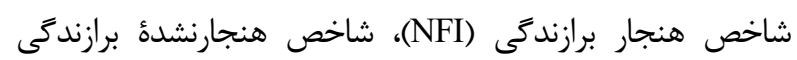

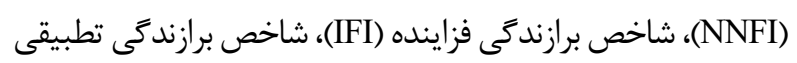
تعاخل)، (CFI)

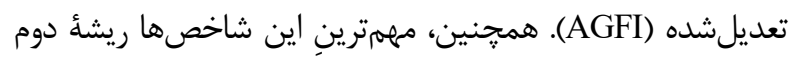
برآورد واريانس خطاى تقريب (AGSEA) همجنين، مهرترين اين شاخد تحليل مدل تحقيق به كار زرفته شد.

\section{مدل سازى معادلات ساختارى فرضيات يزوهش}

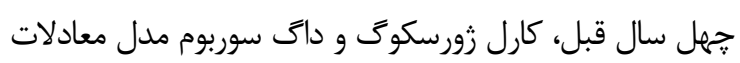

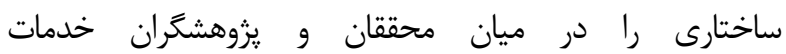

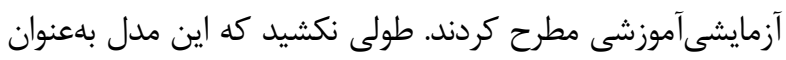

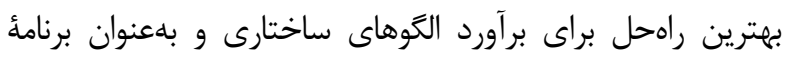

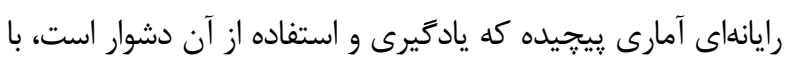

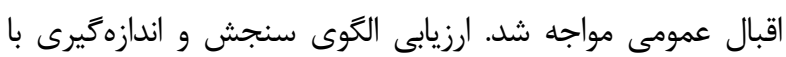

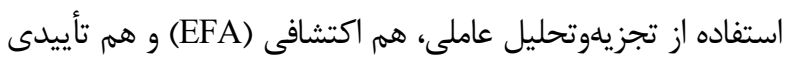

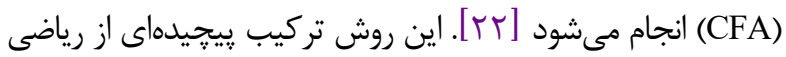



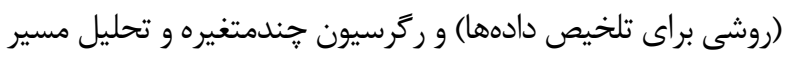

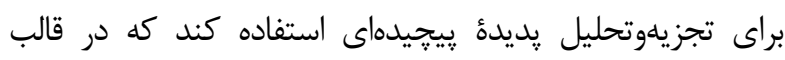

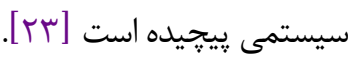

جدول r. شاخصهاى برازندكى مدل در مدل معادلات ساختارى

\begin{tabular}{|c|c|c|}
\hline مقادير محاسبهشده & معيار پذيرش & شاخصها \\
\hline I/FF & 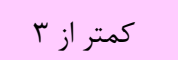 & 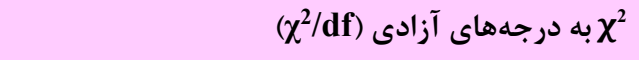 \\
\hline $.1 \cdot 9$ & 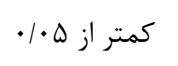 & ريشه ميانغين مربعات باقىمانده (RMR) \\
\hline$\cdot 191$ & 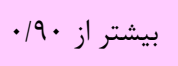 & شاخص هنجار برازندكى (NFI) \\
\hline .199 &  & شاخص هنجارنشدهٔ برازندكى (NNFI) \\
\hline .199 & 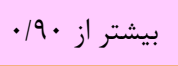 & شاخص برازندگى فزاينده (IFI) \\
\hline$\cdot 199$ & 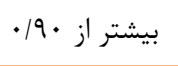 & شاخص برازندكى تطبيقى (CFI) \\
\hline$\cdot 191$ & 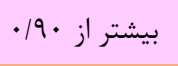 & شاخص نيكويى برازش (GFI) \\
\hline$\cdot 194$ &  & شاخص نيكويى برازش تعديلشده (AGFI) \\
\hline$\cdot / \cdot \Delta r$ & 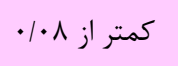 & ريشهُ دوم بر آورد واريانس خطاى تقريب (RMSEA) \\
\hline
\end{tabular}




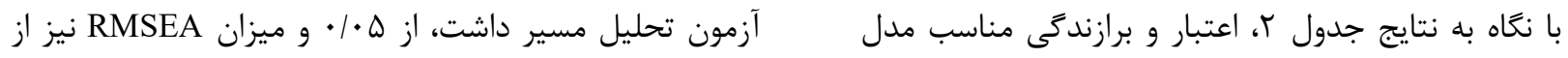

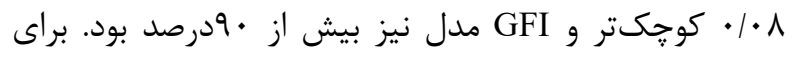

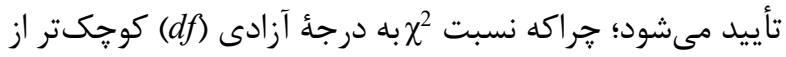

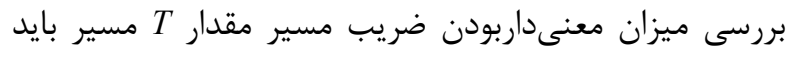

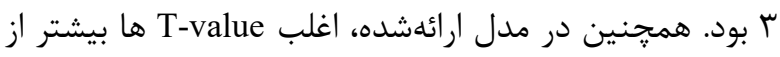



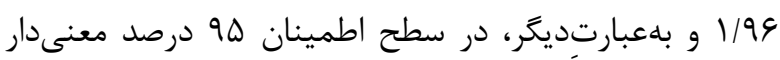

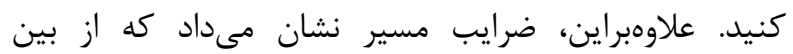
مسيرهاى پيشبينىشده، بيشتر مسيرها معنى دار بود.

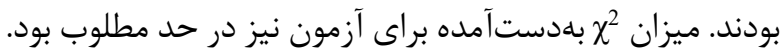
درمقابل، P-value مدل نيز كه حكم سطح معنى بدارى را در



متغير عدالت سازمانى و فعاليتهاى مربوط به مروركرها برابر با

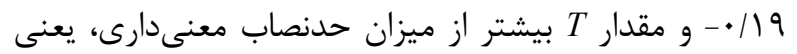

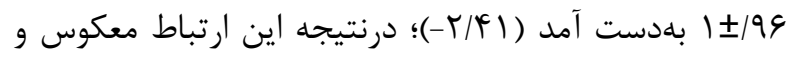



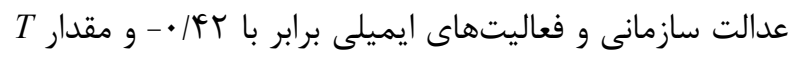

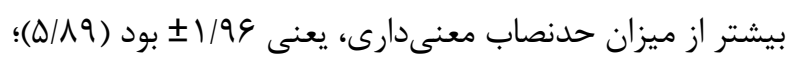
بنابراين، از معنادارى اين ارتباط حكايت مى كرد.
حال بعد از بررسى برازش مدل، مىتوان فرضيات تحقيق

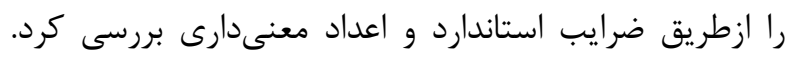

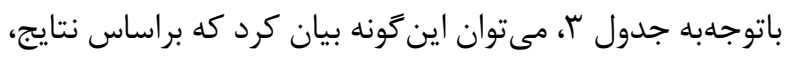
مقدار ضريب مسير براى دو متغير گشتتزنى اينترنتى و عدالت

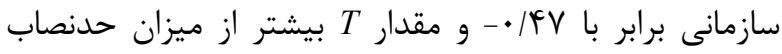

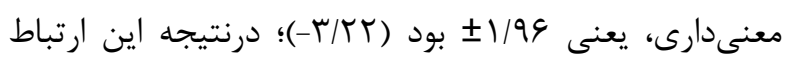

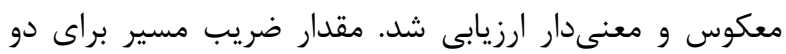

جدول ب. نتايج تحليل مسير ميان متغيرها

رديف

\section{RMSEA = 0.054 ، GFI = 0.98 ، AGFI = 0.94 ، NFI=0.98 NNFI=0.99}

برازش مدل: مجذور خطاهاى مدل (Af

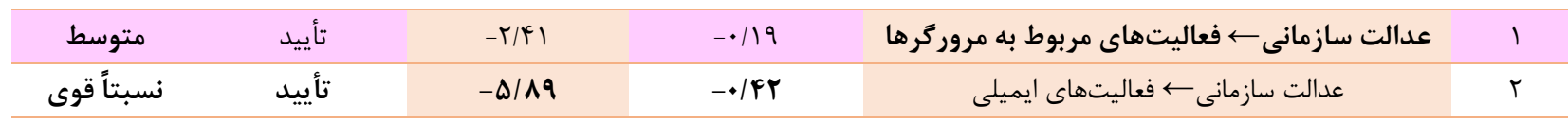


مانند غيبت، ترك شغل، كاهش عملكرد، آسيب به اموال سازمانى و

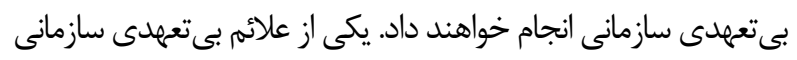

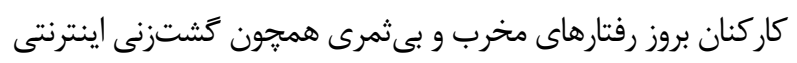
در ساعات كارى است كه بلشدت بر عملكرد شغلى آنان تأثير منفى

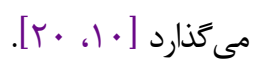

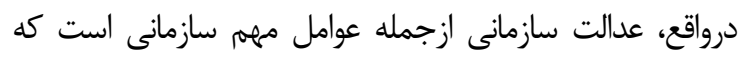

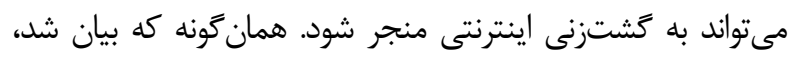

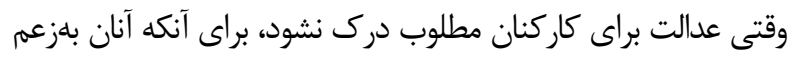

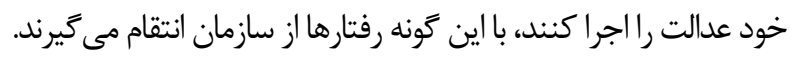
همجنين، در مشاغلى جون بهداشت و درمان كه كاركنان وظايف

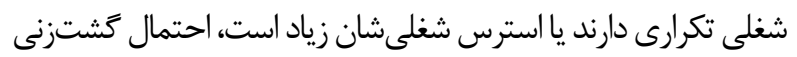

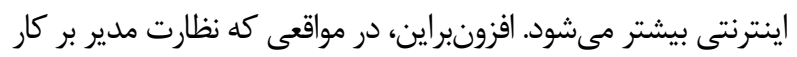



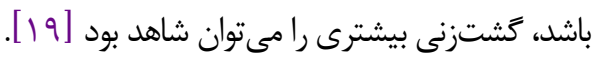

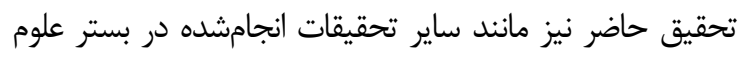

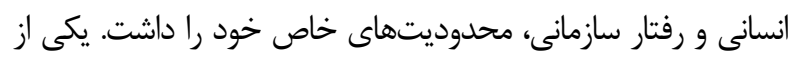

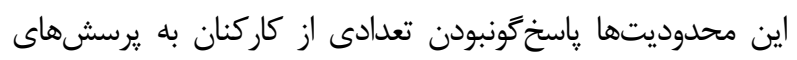
حوزء كشتزنى اينترنتى بود؛ زيرا برخى از كاركنان علاقهمند نبودند إندان اطلاعات مربوط به مسائل شخصى خود را بهاشتراك بكذارند.



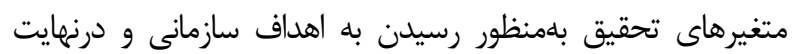

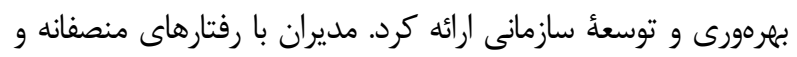

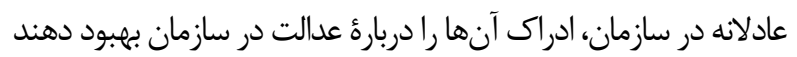
كه اين موضوع درنهايت، به بهبود رضايت شغلى كاركنان منجر ادران

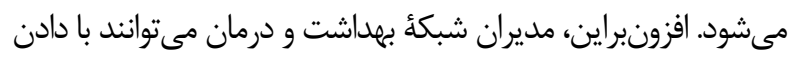
استقلال كارى به كاركنان در انجام رويهها و تصميمات سازمانى، آنان

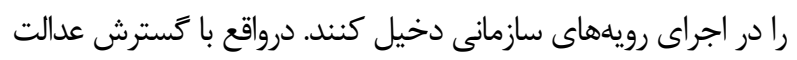
رويالى بلعنوان ميزان ادراك رضايت از فرايندهاى سازمانى و رويهانها،

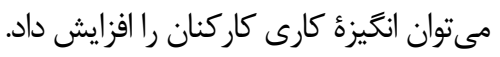

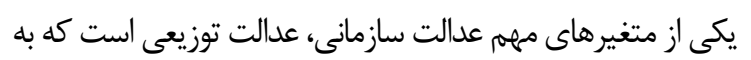

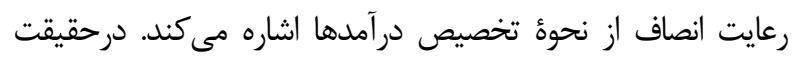

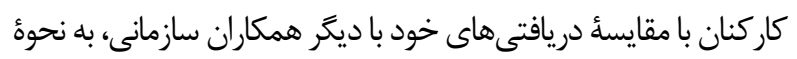

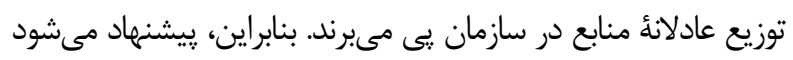

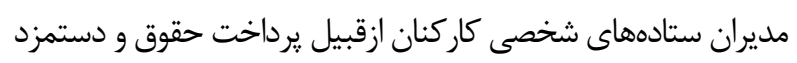

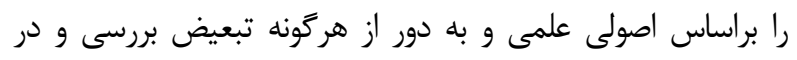

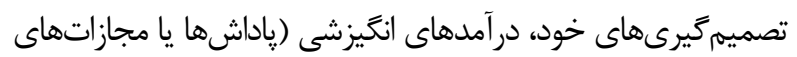

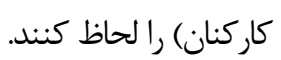

يروهش حاضر با هدف بررسى تأثير ادراك كاركنان از عدالت



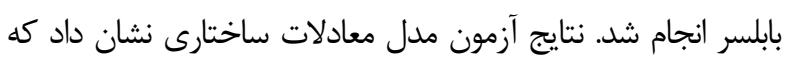

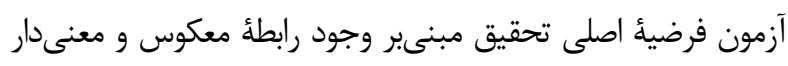

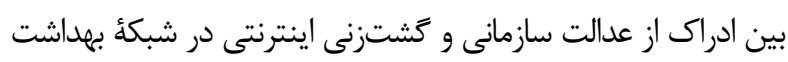

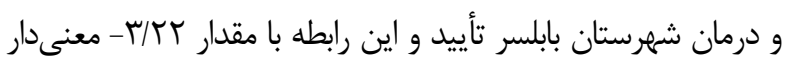

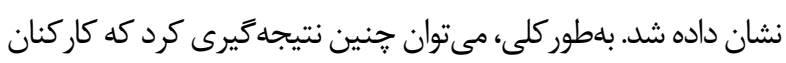

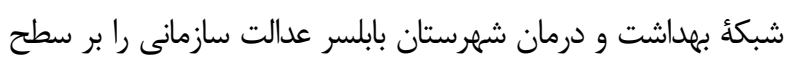

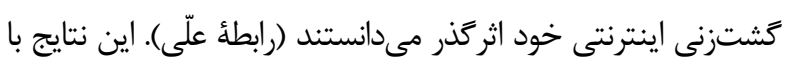



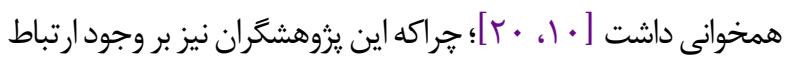

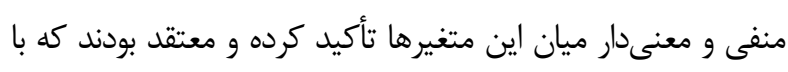



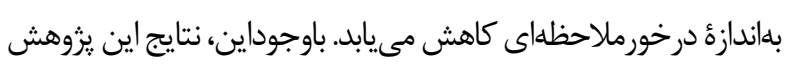

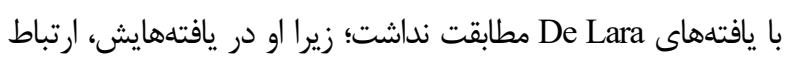
معنى دارى ميان متغيرها كزارش نكرد. در آزمون فرضيات فرعى، وجود ادراى از عدالت سازمانى نيز مئي

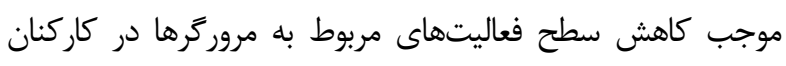

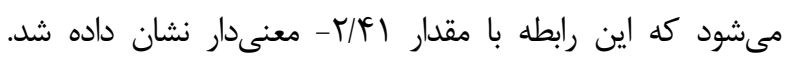

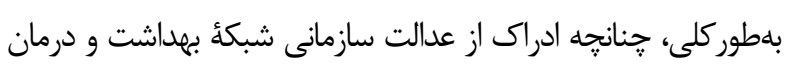



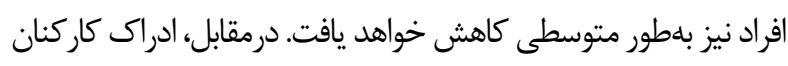



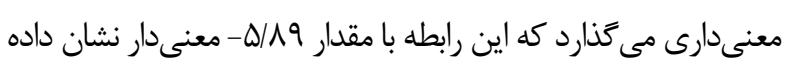

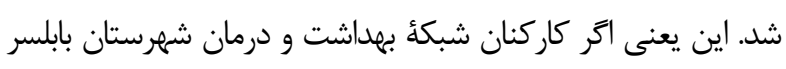

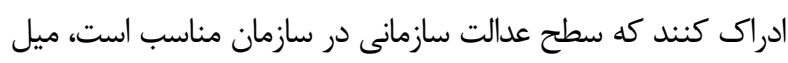

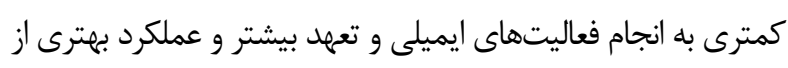

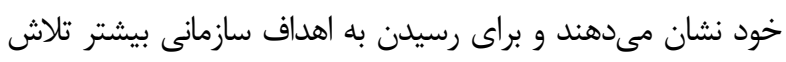

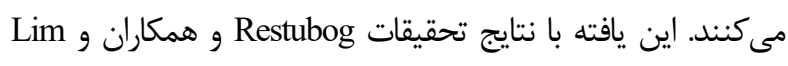

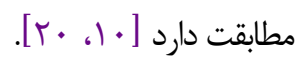
آنجه مسلم است، ادراك كاركنان از عدالت در سازمان بان بر بروز

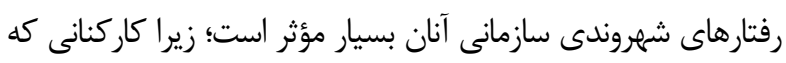

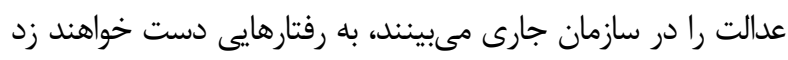

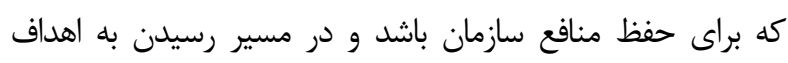

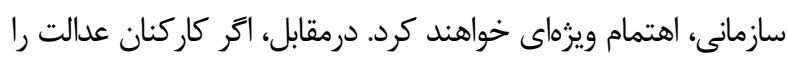






عدالت سازمانى موجب مىشود كاركنان ادراك بهترى از ساير ابعاد عدالت سازمانى ييدا كنند و نظرشان دربارة اين موضوع مساعدتر

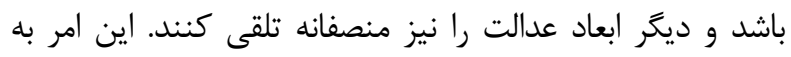

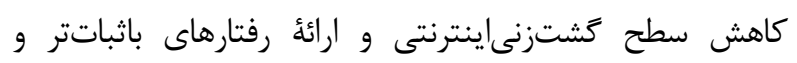

$$
\text { اخلاقىتر منجر مىشود. }
$$

$$
\text { تقدير و تشكر }
$$

محققان اين يزوهش بر خود لازم مىبينند تا از همأ كسانى

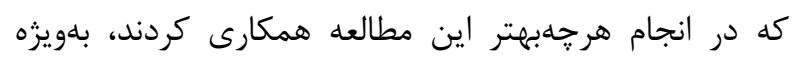
مديران و كاركنان شبكءٔ بهداشت و درمان شهرستان بابلسر، تشكر و قدردانى كنند.

$$
\text { تعارض منافع }
$$

بين نويسندگان هيجَّنه تعارضى در منافع وجود ندارد.

$$
\text { منابع مالى }
$$

منابع مالى اين مطالعه توسط نويسندكان تامين شده است.

\section{References}

1. Zarei E, Ahmadi F, Danshkohan A, Ramezankhani A. The correlation between organizational commitment and the quality of working life among staff of Sarpolzahab health network. J Health Promot Manag. 2016; 5(2): 61-69.

2. Karam EP, Hu J, Davison RB, Juravich M, Nahrgang JD, Humphrey SE, et al. Illuminating the 'face'of justice: A meta-analytic examination of leadership and organizational justice. J Manag Stud. 2019; 56(1): 134-71. [DOI:10.1111/joms.12402]

3. Wolfe SE, Rojek J, Manjarrez Jr VM, Rojek A. Why does organizational justice matter? Uncertainty management among law enforcement officers. J Crim Justice. 2018; 54 : 20-29. [DOI:10.1016/j.jcrimjus.2017.11.003]

4. Greenberg J. Organizational justice: Yesterday, today, and tomorrow. J Manage. 1990; 16(2): 399-432. [DOI:10.1177/014920639001600208]

5. Elamin AM, Alomaim N. Does organizational justice influence job satisfaction and self-perceived performance in Saudi work environment? Int j Manag Rev. 2011; 7(1): 38-49.

6. Rahmanseresht H, Joneidi Jafari M. The effect of organizational justice on organizational citizenship behavior by mediating job commitment in the context of project management. Manag Stud Dev Evol. 2018; 27(87): $127-46$.

$$
\begin{aligned}
& \text { عدالت تعاملى معطوف به كيفيت فرايندهاى بينفردى و رفتار افراد }
\end{aligned}
$$

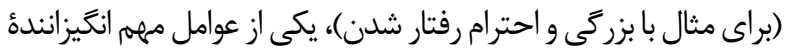

$$
\begin{aligned}
& \text { كارى براى كاركنان است. بنابراين، مديران بايد در تعامل و رفتار با بإن }
\end{aligned}
$$

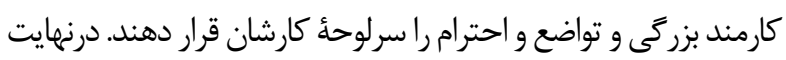

$$
\begin{aligned}
& \text { براى بهبود سطح انخيزش كاركنان، عدالت اطلاعاتى بلعنوان جريان } \\
& \text { عادلانه و شفاف اطلاعات در سازمان را بايد بهبود بخشيد. اين كار }
\end{aligned}
$$



$$
\begin{aligned}
& \text { شفافكردن مسير ييشرفت شغلى براى كاركنان انجام شود. } \\
& \text { نتيجه كَيرى } \\
& \text { درمجموع، نتايج اين يزوهش نشان داد كه ادراك از عدالت } \\
& \text { سازمانى بر سطح كَتزنى اينترنتى در شبكة بهداشت و درمان ئن }
\end{aligned}
$$

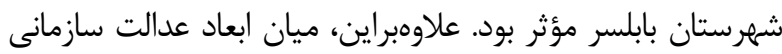

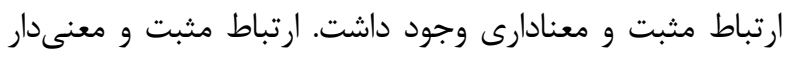

$$
\begin{aligned}
& \text { ابعاد عدالت سازمانى (عدالت توزيعى، عدالت رويهایى، عدالت مدالت } \\
& \text { مراودهاى و عدالت اطلاعاتى) در شبكة بهداشت و درمان شهرستان } \\
& \text { بابلسر اهميت بسزايى دارد؛ زيرا توسعه و بهبود هريك از ابعاد }
\end{aligned}
$$

7. Samadi Miarkolaei H, Samadi Miarkolaei H. An investigation of relation between organizational justice and its components with employs job stress level in the workplace organization. Iran Occup Health. 2015; 12(5): 53-63.

8. Samadi Miarkolaei H, Aghajani H, Samadi Miarkolaei H. Exploration the role of organizational justice and its components on the development of organizational citizenship behavior through (SEM) inference system. J Pub Manag Res. 2015; 8(27): 119-44.

9. Colquitt JA. On the dimensionality of organizational justice: A construct validation of a measure. J App Psychol. 2001; 86(3): 386-400. [DOI:10.1037/0021-9010.86.3.386] [PMID]

10. Lim VLG. The IT way of loafing on the job: Cyberloafing, neutralizing and organizational justice. J Organ Behav. 2002; 23(5): 675-94. [DOI:10.1002/job.161]

11. Aghaz A, Sheikh A. Cyberloafing and job burnout: An investigation in the knowledge-intensive sector. Comput Hum Behav. 2016; 62: 51-60. [DOI:10.1016/j.chb.2016.03.069]

12. Sheikh A, Atashgah MS, Adibzadegan M. The antecedents of cyberloafing: A case study in an Iranian copper industry. Comput Hum Behav. 2015; 51: 172-179. [DOI:10.1016/i.chb.2015.04.042] 
13. Agarwal UA. Impact of Supervisors' Perceived Communication Style on Subordinate's PsyCap and Cyberloafing. Acad Manag Proceed. 2018; 23: 1-27. [DOI:10.5465/AMBPP.2018.11337abstract]

14. Razmi A, Gholipour A, Pirannezhad A. Examining Advances in Cyberloafing. J Organ Cult Manag. 2018; 16(2): 503-19.

15. Lipponen J, Steffens NK, Holtz BC. Prototypical supervisors shape lay-off victims' experiences of top management justice and organizational support. J Occup Organ Psychol. 2018; 91(1): 158-180. [DOI:10.1111/joop.12197]

16. Arab HR, Atan T. Organizational justice and work outcomes in the Kurdistan Region of Iraq. Manag Decis. 2018; 56(4): 808-827. [DOI:10.1108/MD-04-2017-0405]

17. Akbulut Y, Dönmez O, Dursun ÖÖ. Cyberloafing and social desirability bias among students and employees. Comput Hum Behav. 2017; 72: 87-95. [DOI:10.1016/j.chb.2017.02.043]

18. Glassman J, Prosch M, Shao BB. To monitor or not to monitor: Effectiveness of a cyberloafing countermeasure. Inform Manage. 2015; 5I2(2): 170-82. [DOI:10.1016/j.im.2014.08.001]

19. Betts TK, Setterstrom AJ, Pearson JM, Totty S. Explaining Cyberloafing through a Theoretical Integration of Theory of Interpersonal Behavior and Theory of Organizational Justice. J Organ End Use Comput. 2004; 26(4): 23-42. [DOI:10.4018/joeuc.2014100102]
20. Restubog SLD, Garcia PRJM, Toledano LS, Amarnani RK, Tolentino LR, Tang RL. Yielding to (cyber)temptation: Exploring the buffering role of self-control in the relationship between organizational justice and cyberloafing behavior in the workplace. J Res Pers. 2011; 45(2): 247-251. [DOI:10.1016/j.jrp.2011.01.006]

21. De Lara PZ. Relationship between organizational justice and cyberloafing in the workplace: has "anomia" a say in the matter? CyberPsychol Behav. 2007; 10(3): 464-70. [DOI:10.1089/cpb.2006.9931] [PMID]

22. Aghajani H, Samadi Miarkolaei H, Samadi Miarkolaei H. Organizational citizenship behavior's relationship and staffs' psychological empowerment. J Pub Adm. 2013; 5(2):1-19.

23. Samadi Miarkolaei H, Aghajani H, Samadi Miarkolaei H. Exploration and verification of entrepreneurial capacity status in selected universities of Mazandaran province. $\mathrm{J}$ Public Adm. 2015; 7(1):111-32. 